\title{
Sternal tumors surgery: extent of resection, type of reconstruction and survival
}

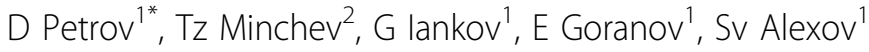 \\ From 23rd World Congress of the World Society of Cardio-Thoracic Surgeons \\ Split, Croatia. 12-15 September 2013
}

\section{Background}

Objective was to evaluate the postoperative results after different sternal resections for malignances.

\section{Methods}

A total of 32 patients (11 males, 21 females, mean age 51.9 years) were operated on during a 7 years period in two institutions. There were 16 sarcomas ( 9 chondrosarcomas, 3 radiation-induced sarcomas, 2 Ewing sarcoma, 2 osteosarcoma), 1 recurrent desmoid tumor, 3 local breast cancer recurrences, 1 plasmocytoma, and 11 metastatic tumors (5 from breast cancer, 2 rabdomyosarcoma, 2 liposarcoma, 1 NSCLC, 1 prostate cancer). Four-five $\mathrm{cm}$ free margins on each side were achieved in all patients with total sternectomy (13), subtotal sternal resection (17), and partial resection (2). Concurrent en bloc resections included anterior ribs (7), clavicle (6), pericardium (2), brachiocephalic vein (2), and diaphragm (1). The chest was reconstructed with Gore-tex (5) or Marlex mesh (22) and myocutaneous flap in 18 (56.25\%) patients or omentum in $6(18.75 \%)$ patients. Only double layer Marlex mesh with breast mobilization was performed in 5 women (15.62\%). Combination of prostetic material and metal bars or wires was needed in 6 patients after total sternectomy (18.75\%). Multimodality treatment pre- or postoperatively was administered in most of the patients.

\section{Results}

There was no 30-day operative mortality. Mechanical ventilation for 5 days was needed in a 78 years old female after total sternectomy. Local suppuration was found in 3 patients. The mean in-hospital stay was 12.7 days. After a median follow-up of 56 months the overall 5-year

\footnotetext{
* Correspondence: danail_petrov@hotmail.com

'Thoracic Surgery Department, Saint Sophia University Hospital of Pulmonary Diseases, Medical University-Sofia, Bulgaria

Full list of author information is available at the end of the article
}

survival was $58 \%$, with a median survival of 61 months. Local recurrence occurred in 3 patients, who underwent a repeat total resection. Metastases developed in 2 patients.

\section{Conclusion}

Wide sternal resection (4-5 cm free margins) is a safe and effective treatment of sternal malignances. The chest wall reconstruction depends on the size and site of the resection, and should be planned with plastic surgeons.

\section{Authors' details}

'Thoracic Surgery Department, Saint Sophia University Hospital of Pulmonary Diseases, Medical University-Sofia, Bulgaria. ${ }^{2}$ Thoracic Surgery Ward, Tokuda Hospital, Sofia, Bulgaria.

Published: 11 September 2013

doi:10.1186/1749-8090-8-S1-0264

Cite this article as: Petrov et al: Sternal tumors surgery: extent of resection, type of reconstruction and survival. Journal of Cardiothoracic Surgery 2013 8(Suppl 1):0264.

Submit your next manuscript to BioMed Central and take full advantage of:

- Convenient online submission

- Thorough peer review

- No space constraints or color figure charges

- Immediate publication on acceptance

- Inclusion in PubMed, CAS, Scopus and Google Scholar

- Research which is freely available for redistribution

Submit your manuscript at www.biomedcentral.com/submit 